\title{
Cognitive-behavioral therapy for treatment-resistant depression in adults and adolescents: a systematic review
}

\author{
Terapia cognitivo-comportamental para depressão resistente ao tratamento em \\ adultos e adolescentes: uma revisão sistemática
}

\author{
Stephanie Zakhour, ${ }^{1}$ (ID Antonio E. Nardi, ${ }^{1}$ Michelle Levitan, ${ }^{1}$ Jose Carlos Appolinario ${ }^{1,2,3,4}$
}

\begin{abstract}
Objective: To conduct a systematic review of literature on use and efficacy of cognitive-behavioral therapy (CBT) for treatment of treatment-resistant depression in adults and adolescents.

Methods: We performed a systematic review according to the Prisma Guidelines of literature indexed on the PubMed, SciELO, Psychiatry Online, Scopus, PsycArticles, Science Direct and the Journal of Medical Case Reports databases. Randomized controlled trials, open studies and case reports were included in the review.

Results: The searches returned a total of 1,580 articles, published from 1985 to 2017. After applying the inclusion criteria, 17 articles were selected, their complete texts were read and 8 were included in this review. Four of these studies were randomized controlled trials with adults, one of which covered a post-study follow-up period; two were randomized controlled trials with adolescents, one of which presented follow-up data; one was an open study; and one was a case report. The studies provide good quality and robust evidence on the topic addressed.

Conclusions: A combination of CBT with pharmacotherapy for treatment-resistant patients shows a decrease in depressive symptoms. CBT can be an effective type of therapy for adults and adolescents with treatment-resistant depression.
\end{abstract}

Keywords: Cognitive-behavioral therapy, major depressive disorder, treatment-resistant depressive disorder.

\section{Resumo}

Objetivos: Realizar uma revisão sistemática sobre o uso da terapia cognitivo-comportamental (TCC) e sua eficácia no tratamento da depressão resistente ao tratamento em adultos e adolescentes.

Métodos: Realizamos uma revisão sistemática utilizando os critérios do Prisma Guidelines, nos seguintes bancos de dados: PubMed, SciELO, Psychiatry Online, Scopus, PsycArticles, Science Direct e Journal of Medical Case Reports. Estudos controlados randomizados, estudos abertos e relatos de casos foram incluídos neste estudo.

Resultados: A pesquisa retornou um total de 1.580 artigos, publicados de 1985 até 2017. Após aplicarmos os critérios de inclusão, 17 artigos foram selecionados, seus textos completos foram lidos e 8 foram incluídos nesta revisão. Do total, quatro eram estudos controlados randomizados com adultos, tendo um incluído um período de seguimento pós-estudo; dois eram estudos controlados randomizados com adolescentes, tendo um apresentado dados de seguimento; um era um estudo aberto; e o último era um relato de caso. Os estudos apresentaram boa qualidade e evidências robustas sobre o tópico abordado.

Conclusões: A combinação de TCC com tratamento medicamentoso para pacientes resistentes ao tratamento mostra uma diminuição dos sintomas depressivos. A TCC pode ser um tipo eficaz de terapia para adultos e adolescentes com depressão resistente ao tratamento.

Descritores: Terapia cognitivo-comportamental, transtorno depressivo maior, transtorno depressivo resistente a tratamento.

\footnotetext{
${ }^{1}$ Ambulatório de Depressão Resistente ao Tratamento (DeReTrat), Instituto de Psiquiatria (IPUB), Universidade Federal do Rio de Janeiro (UFRJ), Rio de Janeiro, RJ, Brazil. ${ }^{2}$ Programa de Pós-Graduação, IPUB, UFRJ, Rio de Janeiro, RJ, Brazil. ${ }^{3}$ Grupo de Obesidade e Transtornos Alimentares, IPUB, UFRJ, Rio de Janeiro, RJ, Brazil. ${ }^{4}$ Instituto Estadual de Diabetes e Endocrinologia Luiz Capriglione (IEDE), UFRJ, Rio de Janeiro, Brazil. Submitted Dec 12 2018, accepted for publication May 12 2019. Epub Mar 022020.

Suggested citation: Zakhour S, Nardi AE, Levitan M, Appolinario JC. Cognitive-behavioral therapy for treatment-resistant depression in adults and adolescents: a systematic review. Trends Psychiatry Psychother. 2020;42(1):92-101. http://dx.doi.org/10.1590/2237-6089-2019-0033
} 


\section{Introduction}

Treatment-resistant depression (TRD) is diagnosed when patients who suffer from major depressive disorder (MDD) are unable to achieve an adequate therapeutic response despite using one or more antidepressants. ${ }^{1}$ TRD is a relatively common occurrence in clinical practice with adult populations, with up to 50 to $60 \%$ of patients not achieving adequate response following antidepressant treatment. ${ }^{2}$ Moreover, only about $60 \%$ of adolescents with depression will show an adequate clinical response to antidepressant treatment. ${ }^{3}$ In addition, $40 \%$ of adolescents will not respond to treatment and thus suffer from TRD. TRD is associated with greater severity than MDD and is associated with risk of suicide. A study by Bergfeld et al. ${ }^{4}$ showed that $30 \%$ of patients with TRD attempt suicide at least once during their lifetime.

The usual treatment for moderate to severe depression (also called treatment as usual [TAU]) is based on use of medication such as selective serotonin reuptake inhibitor (SSRI) antidepressants. Although this treatment has shown efficacy in some cases, many will not respond to treatment even after several trials. ${ }^{5}$ Therefore, treating TRD is a considerable challenge. Several pharmacological strategies have been proposed to deal with patients who do not respond to TAU and these interventions include combined treatments. Many studies have shown the importance of psychotherapy in combination with TAU as an important strategy for management of TRD.

Nakagawa et al. ${ }^{6}$ conducted a randomized controlled trial with the aim of investigating the effectiveness of CBT in TRD patients. Their study included outpatients randomly assigned to CBT combined with TAU or to TAU alone and the primary outcome was alleviation of depressive symptoms. They found that supplementary CBT alleviated depressive symptoms at 16 weeks and that the treatment effect was maintained for at least 12 months.

Other authors have tested the efficacy of this strategy in an adolescent population. Brent et al. ${ }^{3}$ conducted a randomized controlled study (TORDIA) with the objective of evaluating the best treatment option for adolescents aged 12 to 18 years (either switching medications or adding CBT to the treatment). Participants were treated for 12 weeks (TAU alone and TAU+CBT) and the results showed that for adolescents with depression that did not respond to TAU, the combination of CBT with switching to another medication resulted in a higher rate of clinical response than a medication switch alone.

A recent systematic review and meta-analysis by Li et al. ${ }^{7}$ assessed the effectiveness of CBT and other related interventions for treatment of patients with TRD. The authors included randomized controlled trials performed with adults over 18 years old who were suffering from TRD and were allocated to CBT and/or other forms of interventions. Patients were assessed using validated designed to assess depression, such as the 17-item Hamilton Rating Scale for Depression (HRSD-17), the 21item Hamilton Rating Scale for Depression (HAMD-21), the Beck Depression Inventory-II (BDI-II) or the Patient Health Questionnaire-9 (PHQ-9). The authors selected six out of 526 studies identified: two trials that used CBT, two trials that applied mindfulness-based cognitive therapy (MBCT), one that adapted rumination-focused cognitive-behavioral therapy (RFCBT) and one that used smartphone CBT. They reported that these interventions were effective for treatment of TRD symptoms and that the effects were maintained at 6-month follow-up. However, one of the most significant criticisms of this review is that inclusion of several different types of CBT and CBT-based interventions could have impacted the findings. There is a need to look at more homogeneous intervention groups such as CBT alone or MBCT alone.

The purpose of this review therefore differs from the one described above because our aim is to conduct a systematic review to examine the efficacy of CBT alone, with no other CBT based interventions, for treatment and alleviation of depressive symptoms in TRD. Moreover, to examine whether CBT reduces depressive symptoms in TRD compared to TAU alone, our study included randomized controlled trials, open trials and case reports and is not restricted to adult populations, but also includes studies with adolescents (age $<18$ ), since few studies have addressed this subset.

\section{Methods}

We followed the Preferred Reporting Items for Systematic Review and Meta-Analyses (PRISMA) guidelines throughout this systematic review. ${ }^{8}$

\section{Eligibility criteria}

Studies were selected and included in the present review according to the following criteria: 1) studies assessing the efficacy of $C B T$ in TRD, 2) randomized controlled trials (RCTs), long-term follow-up studies derived from RCTs, open trials and case studies are included, 3) inclusion of participants that meet criteria for TRD defined in Trevino et al., ${ }^{1} 4$ ) inclusion of studies that only use face-to-face CBT as a treatment model, 5 ) inclusion of both adolescent (12-18 years old) and adult populations, and 6) inclusion of studies that used validated instruments to assess depressive symptoms. 


\section{Information source and search strategy}

Searches were run on PubMed, SciELO, Psychiatry Online, Scopus, PsycArticles, Science Direct, and the Journal of Medical Case Reports using combinations of the Medical Subject Headings (MeSH) terms "cognitive behavioral therapy," "cognitive behavior therapy," "cognitive psychotherapy", "cognitive therapy", "cognition therapy," "treatment-resistant depression", "refractory depression" and "therapy resistant depression". Additional records were identified from other sources by searching references lists of the studies found in databases. The search was last run on April 8, 2019. No restriction was placed on language of publication.

\section{Study selection}

The lead author of this study independently screened the articles identified for appropriateness for inclusion. Non-randomized controlled trials, literature review studies, systematic reviews and studies that used types of therapy other than CBT were excluded from the systematic review.

\section{Data collection process and data items}

Data collection was conducted independently by the lead author of this systematic review. The titles and abstracts identified by the initial search were screened to determine their relevance to the review. Articles that did not meet the inclusion criteria were excluded at this stage and then the full texts of potentially relevant studies were examined. The lead author of this review selected articles independently.

\section{Risk of bias in individual studies}

Only the randomized controlled trials selected for the review study were assessed for quality and risk of bias. The Randomized Controlled Trial Psychotherapy Quality Rating Scale (RCT-PQRS) was used. ${ }^{9}$

\section{Data synthesis}

This systematic review is presented as a narrative synthesis measuring the efficacy of adding CBT treatment for adults and adolescents who suffer from TRD.

\section{Results}

\section{Study selection}

A total of 1,576 articles were found by database searches. Additional records $(n=4)$ were identified by searching the references lists of the studies found. Hence, a total of 1,580 articles published from 1985 to 2017 were identified for the systematic review. After removing duplicate articles $(n=19)$ and excluding studies on the basis of title ( $n=1535), 26$ were retained for further consideration. Nine of these were excluded after reading the abstracts. Nine of the 17 remaining articles assessed for eligibility were excluded after reading the full texts, because they did not meet inclusion criteria and were non-randomized controlled studies. Finally, 8 studies were included in the systematic review: 4 randomized controlled trials, ${ }^{6,10-12}$ one of which is a long-term follow-up RCT ${ }^{11}$ assessing the efficacy of CBT in adults suffering from TRD; 2 randomized controlled trials $^{3,13}$ assessing the efficacy of CBT in adolescents suffering from TRD, one of which is a long-term followup $\mathrm{RCT}^{13} ; 1$ open trial ${ }^{14}$; and 1 case report. ${ }^{15}$ The search and selection process for articles is illustrated in a flow diagram (see Figure 1).

\section{Study characteristics}

Participants' characteristics

A total of 1,056 patients were enrolled in the 8 studies analyzed in this systematic review, 722 of whom were adults and 334 of whom were adolescents. Of these, 364 adults (78.16\% female, mean age 30.68 ) and 166 adolescents (69.9\% female, mean age 16.0 ) received $\mathrm{CBT}$ treatment in addition to TAU, compared to 358 adults (65.1\% female, mean age 44.9$)$ and 168 adolescents $(69.6 \%$ female, mean age 15.8$)$ who received TAU alone. Six of the studies included both genders, ${ }^{3,6,10-14}$ while two of them only included women. ${ }^{14,15}$

\section{Methods}

Six studies $3,6,10-13$ selected for the review were randomized controlled trials published in English. The participants in these studies were randomly assigned to different types of intervention groups in order to compare them and detect results. One study ${ }^{14}$ was an open trial using only one group of participants and administering the intervention to all participants. Finally, one study ${ }^{15}$ was a case report that used the case of a woman receiving individual CBT therapy to illustrate whether CBT is effective for TRD.

\section{Intervention characteristics}

The randomized controlled trials in this systematic review analyzed two types of interventions: TAU alone or TAU + CBT. Participants in the open trial study ${ }^{14}$ and the case study ${ }^{15}$ received only CBT as treatment modality. In all cases, TAU was prescribed by psychiatrists: TAU is treatment of these patients with medication only. Psychiatrists usually use SSRI antidepressants for TAU. In the studies included in this systematic review, CBT was facilitated by therapists with at least a masters 
degree in a mental health field and prior experience in $\mathrm{CBT}^{3,15}$; by four psychiatrists, 1 clinical psychologist with a Masters degree and 1 psychiatric nurse ${ }^{6}$; by two experienced and well-trained therapists under the supervision of a PhD-level clinical psychologist who had six years' experience in treating depressed patients with cognitive therapy ${ }^{14}$; by therapists who received at least 1 day of training specific to the trial from an experienced CBT therapist and trainer and weekly supervision from skilled CBT supervisors at each center ${ }^{11}$; and, finally, by therapists with a master's degree in a mental health field and a license permitting provision of therapy, trained for 35 hours in a face-to-face workshop. ${ }^{12}$ All of the participants were assessed with validated scales that assess depressive symptoms and most of them were followed-up for at least 12 months after intervention.
Table 1 lists additional descriptive characteristics, the first author, year of publication, study design, intervention, session length, duration of follow-up, instruments and main findings.

\section{Outcomes}

In all studies, the primary outcome assessed was alleviation of depressive symptoms measured using validated scales and compared from baseline to at least 12-month follow-up and as much as 40-month follow-up.

\section{Risk of bias within studies}

We utilized the RCT-PQRS to assess the risk of bias in individual studies. ${ }^{9}$ The results are summarized in Tables 2 and 3 . Only the randomized controlled trials

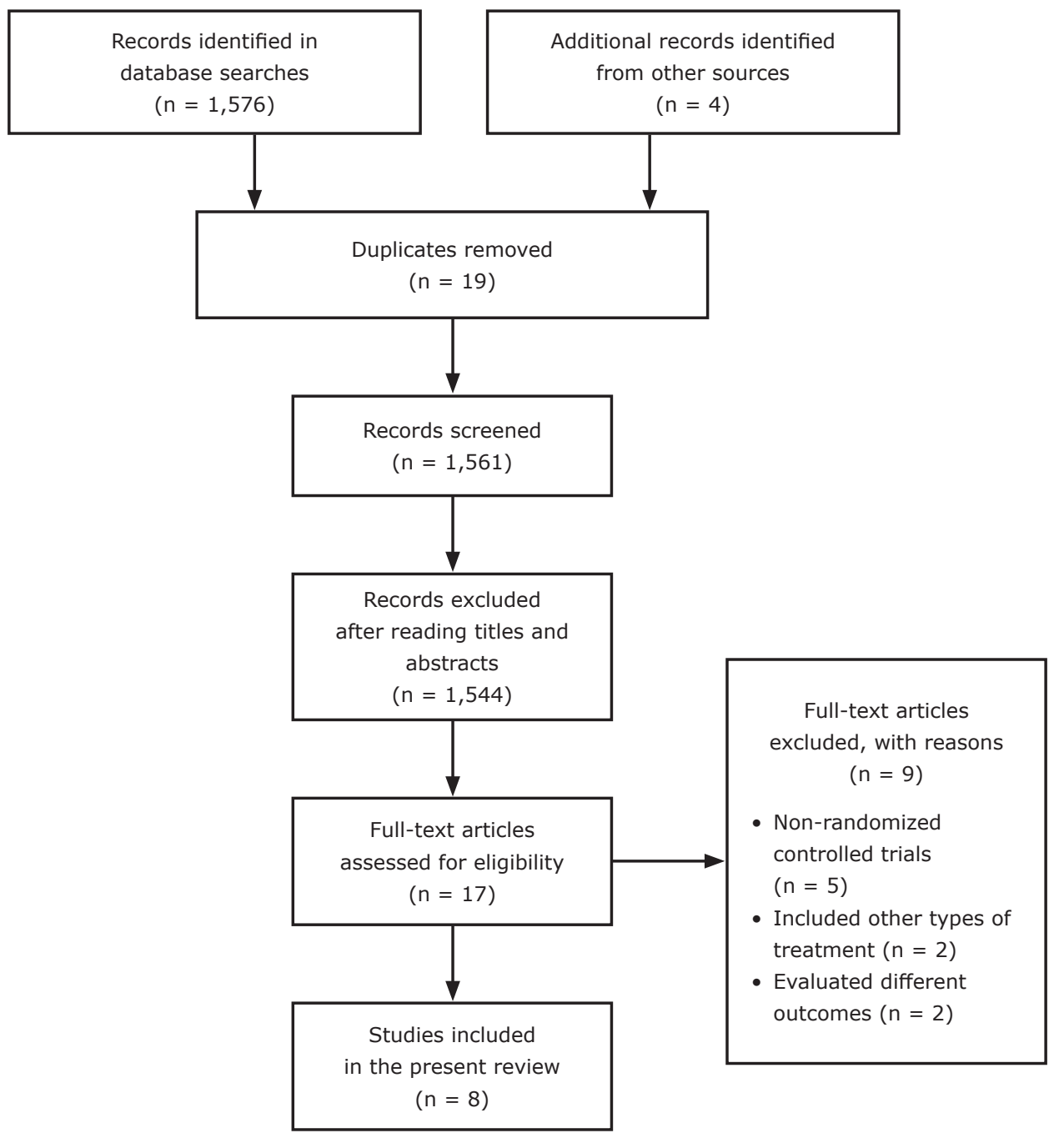

Figure 1 - Prisma flow diagram illustrating study selection process. 
were assessed for quality and risk of bias. All randomized controlled studies were rated as low risk of bias.

\section{Results of individual studies}

Randomized controlled trials

In a randomized controlled trial by Nakagawa et al., ${ }^{6}$ a total of 80 patients aged $20-65$ years old (mean $=39.5$ ) were selected to participate in the study. All participants had at least a minimal degree of TRD and a score of $\geq 16$ on the GRID-Hamilton Depression Rating Scale (GRIDHDRS). All eligible participants were randomly allocated to receive CBT plus TAU or TAU alone with 12-month follow-up. Those who received CBT plus TAU were offered 16 individual 50-minutes sessions scheduled weekly with up to 4 additional sessions. SSRIs were the most common antidepressant medication prescribed for the TAU only group. The primary outcome of this study was alleviation of depressive symptoms measured by

Table 1 - Descriptive details of studies included in this systematic review

\begin{tabular}{|c|c|c|c|c|c|c|c|c|}
\hline First author & $\begin{array}{c}\text { Year of } \\
\text { publication }\end{array}$ & $\begin{array}{l}\text { Study } \\
\text { design }\end{array}$ & Intervention & $\begin{array}{l}\text { Frequency and } \\
\text { duration of } \\
\text { intervention }\end{array}$ & $\begin{array}{l}\text { Session } \\
\text { length }\end{array}$ & $\begin{array}{l}\text { Duration } \\
\text { of follow- } \\
\text { up }\end{array}$ & Instruments & Main findings \\
\hline Brent $^{3}$ & 2008 & RCT & $\mathrm{TAU}, \mathrm{CBT}$ & 12 weeks & $\begin{array}{l}\text { TAU: } 30-60 \\
\text { minutes } \\
\text { CBT: } 60-90 \\
\text { minutes }\end{array}$ & $\begin{array}{l}6 \text { and } 12 \\
\text { weeks }\end{array}$ & $\begin{array}{l}\text { CDRS-R, BDI, } \\
\text { SIQ-Jr, CGI-I, } \\
\text { CGAS }\end{array}$ & $\begin{array}{c}\text { CBT plus a switch to either } \\
\text { medication regimen showed a } \\
\text { higher response rate }(54.8 \%) \text { than } \\
\text { a medication switch alone }(40.5 \%) \\
\text { and there was no difference in } \\
\text { response rate between venlafaxine } \\
\text { and a second SSRI. }\end{array}$ \\
\hline Nakagawa ${ }^{6}$ & 2017 & $\mathrm{RCT}$ & $\begin{array}{l}\text { TAU, Individual } \\
\text { CBT }\end{array}$ & $\begin{array}{l}16 \text { sessions }+ \\
4 \text { additional } \\
\text { sessions }\end{array}$ & 50 minutes & 12 months & $\begin{array}{l}\text { GRID-HDRS, } \\
\text { QIDS-SR, } \\
\text { HPQ }\end{array}$ & $\begin{array}{l}\text { Patients with TRD may benefit } \\
\text { from supplementing TAU with CBT. }\end{array}$ \\
\hline Wiles $^{10}$ & 2013 & RCT & $\begin{array}{l}\text { TAU, Individual } \\
\text { CBT }\end{array}$ & $\begin{array}{l}12 \text { sessions }+ \\
6 \text { additional } \\
\text { sessions }\end{array}$ & $\begin{array}{l}50-60 \\
\text { minutes }\end{array}$ & 12 months & BDI, ICD-10 & $\begin{array}{l}\text { CBT + TAU was effective for } \\
\text { reducing depressive symptoms and } \\
\text { improving quality of life in patients } \\
\text { with TRD. }\end{array}$ \\
\hline Wiles $^{11}$ & 2016 & $\begin{array}{l}\text { Follow- } \\
\text { Up RCT }\end{array}$ & $\begin{array}{l}\text { TAU, Individual } \\
\text { CBT }\end{array}$ & $\begin{array}{l}12 \text { sessions }+ \\
6 \text { additional } \\
\text { sessions }\end{array}$ & $\begin{array}{l}50-60 \\
\text { minutes }\end{array}$ & 3-5 years & $\begin{array}{l}\text { BDI, SF-12, } \\
\text { PHQ-9, GAD- } \\
\text { 7, EQ-5D-5L }\end{array}$ & $\begin{array}{l}\text { The CBT intervention reduced } \\
\text { depressive symptoms and } \\
\text { improved quality of life over an } \\
\text { average of } 46 \text { months. }\end{array}$ \\
\hline Lope $^{12}$ & 2014 & RCT & $\begin{array}{l}\text { TAU, Individual } \\
\text { CBT }\end{array}$ & 18 sessions & NM & IAI & BDI, QIDS & $\begin{array}{c}\text { Participants showed a more } \\
\text { rapid reduction in depressive } \\
\text { symptoms over time and more CBT } \\
\text { participants reached full symptom } \\
\text { remission. }\end{array}$ \\
\hline Emslie $^{13}$ & 2010 & RCT & TAU, CBT & 12 weeks & $\begin{array}{l}\text { TAU: } 30-60 \\
\text { minutes } \\
\text { CBT: } 60-90 \\
\text { minutes }\end{array}$ & 24 weeks & $\begin{array}{l}\text { CDRS-R, BDI, } \\
\text { CGAS, CGIS, } \\
\text { BHS, SIQ- } \\
\text { Jr, CBQ-A, } \\
\text { DUS-U, DUS-I }\end{array}$ & $\begin{array}{l}\text { Of the } 334 \text { adolescents, only } 261 \\
\text { participants ( } 78.1 \%) \text { were included } \\
\text { in the } 24 \text {-week assessment } \\
\text { and } 20 \% \text { did not complete } \\
\text { the assessment. The results } \\
\text { showed that only } 38.9 \% \text { of } 334 \\
\text { adolescents on the TORDIA trial } \\
\text { achieved remission by } 24 \text { weeks. }\end{array}$ \\
\hline Miller ${ }^{14}$ & 1985 & $\begin{array}{l}\text { Open } \\
\text { trial }\end{array}$ & TAU, CBT, SST & $\begin{array}{l}28 \text { sessions } \\
\text { over a period } \\
\text { averaging } 22 \\
\text { weeks }\end{array}$ & NM & IAI & BDI, HDRS & $\begin{array}{l}4 \text { of the } 6 \text { patients exhibited } \\
\text { complete improvement on } \\
\text { measures of depression } \\
\text { symptomatology. }\end{array}$ \\
\hline Bannan $^{15}$ & 2005 & $\begin{array}{l}\text { Case } \\
\text { report }\end{array}$ & $\begin{array}{l}\text { Venlafaxine, } \\
\text { CBT }\end{array}$ & $\begin{array}{l}12 \text { sessions } \\
\quad(\mathrm{CBT}) \\
375 \mathrm{mg} \text { daily } \\
\text { (venlafaxine) }\end{array}$ & NM & IAI & BDI, BHI, BAI & $\begin{array}{l}\text { Clear improvements on } \\
\text { assessments of mood and } \\
\text { hopelessness and in social and } \\
\text { occupational functioning. }\end{array}$ \\
\hline
\end{tabular}

BAI = Beck Anxiety Inventory; BDI = Beck Depression Inventory; BHI = Beck Hopelessness Inventory; BHS = Beck Hopelessness Scale; CBQ-A = Conflict Behavior Questionnaire - Adolescent version; CBT = cognitive-behavioral therapy; CDRS-R = Children's Depression Rating Scale Revised; CGAS = Children's Global Assessment Scale; CGI-I = Clinical Global Impressions-Improvement Subscale; CGIS = Clinical Global Impression Severity; DUS-I = Drug Use Screening Inventory - Impairment; DUS-U = Drug Use Screening Inventory - Use; EQ-5D-5L = standardized generic measure of health status used as part of the economic evaluation; GAD-7 = 7-Item Generalized Anxiety Disorder assessment; GRID-HDRS = 17-item GRID-Hamilton Depression Rating Scale; HDRS = Hamilton Depression Rating Scale; HPQ = Work Performance Questionnaire; IAI = immediately after intervention; ICD-10 = International Classification of Disease; NM = not mentioned; PHQ-9 = Patient Health Questionnaire-9; QIDS-SR = Depressive Symptomatology Self-Report; RCT = randomized controlled trial; SF-12 = 12-Item Short-Form Health Survey; SIQ-Jr = Suicide Ideation Questionnaire-Jr-4; SST = social skills training; TAU = treatment as usual (pharmacotherapy); TRD = treatment-resistant depression. 
the GRID-HDRS. The results showed that alleviation of depressive symptoms at 16 weeks was greater in the CBT group than in the TAU group and that the beneficial effects of CBT were maintained over the 12-month follow-up period. $82.5 \%$ of those receiving CBT + TAU and $50 \%$ of those receiving TAU alone showed a $\geq 50 \%$ reduction in the GRID-HDRS.

The CoBalT randomized controlled trial by Wiles et al. ${ }^{10}$ recruited 469 patients aged $18-75$ years (mean 49.2) who had been compliant with an adequate dose of antidepressant medication for at least 6 weeks and who all had a BDI score of 14 or more (mean 31.8 ). Participants with other disorders such as bipolar or psychotic disorder were excluded, as were participants who received CBT treatment in the previous 3 years. Participants were taking antidepressants at the time of randomization and were expected to continue with the drugs. In addition, they were randomly allocated to receive CBT plus TAU or TAU alone. Those who received $C B T+T A U$ received 12 sessions of individual CBT lasting 50-60 minutes with a further six sessions: $90 \%$ of patients were followed up at 6 months and $84 \%$

Table 2 - Randomized controlled trials of Psychotherapy Quality Rating Scale scores for clinical trials of cognitive-behavioral therapy for treatment-resistant depression

\begin{tabular}{|c|c|c|c|c|}
\hline & Brent $^{3}$ & Nakagawa7 & Wiles $^{12}$ & Lopez $^{13}$ \\
\hline \multicolumn{5}{|l|}{ Description of subjects } \\
\hline 1. Diagnostic method and inclusion/exclusion criteria & 2 & 2 & 2 & 1 \\
\hline 2. Documentation/demonstration of reliability of diagnostic methodology & 1 & 1 & 2 & 0 \\
\hline 3. Description of relevant comorbidities & 2 & 2 & 2 & 1 \\
\hline 4. Description of numbers of subjects screened, included, and excluded & 2 & 2 & 2 & 2 \\
\hline \multicolumn{5}{|l|}{ Definition and delivery of treatment } \\
\hline $\begin{array}{l}\text { 5. Treatment(s) (including control/comparison groups) are sufficiently } \\
\text { described or referenced to allow for replication }\end{array}$ & 2 & 2 & 2 & 2 \\
\hline 6. The treatment being studied is treatment delivered & 2 & 2 & 2 & 2 \\
\hline $\begin{array}{l}\text { 7. Therapist training and level of experience in the treatment(s) under } \\
\text { investigation }\end{array}$ & 2 & 2 & 2 & 2 \\
\hline 8. Therapist supervision while treatment is being provided & 2 & 1 & 2 & 2 \\
\hline 9. Description of concurrent treatments allowed and administered & 2 & 1 & 1 & 0 \\
\hline \multicolumn{5}{|l|}{ Outcome measures } \\
\hline 10. Validated outcome measure(s) & 2 & 2 & 2 & 2 \\
\hline 11. Primary outcome measure(s) specified in advance & 2 & 2 & 2 & 0 \\
\hline $\begin{array}{l}\text { 12. Outcome assessment by raters blinded to treatment group and with } \\
\text { established reliability }\end{array}$ & 2 & 0 & 0 & 0 \\
\hline 13. Discussion of safety and adverse events during study treatment(s) & 2 & 0 & 0 & 0 \\
\hline 14. Assessment of long-term post-termination outcome & 1 & 1 & 1 & 1 \\
\hline \multicolumn{5}{|l|}{ Data analysis } \\
\hline 15. Intent-to-treat method for data analysis, primary outcome & 2 & 2 & 2 & 0 \\
\hline 16. Description of dropouts and withdrawals & 2 & 2 & 2 & 1 \\
\hline 17. Appropriate statistical tests & 2 & 2 & 2 & 1 \\
\hline 18. Adequate sample size & 2 & 2 & 1 & 1 \\
\hline 19. Appropriate consideration of therapist and site effects & 2 & 1 & 1 & 1 \\
\hline \multicolumn{5}{|l|}{ Treatment assignment } \\
\hline 20. A priori relevant hypotheses that justify comparison group(s) & 2 & 1 & 2 & 1 \\
\hline $\begin{array}{l}\text { 21. Comparison group(s) from same population and time frame as } \\
\text { experimental group }\end{array}$ & 2 & 2 & 2 & 2 \\
\hline 22. Randomized assignment to treatment groups & 2 & 2 & 2 & 2 \\
\hline \multicolumn{5}{|l|}{ Overall quality of study } \\
\hline 23. Balance of allegiance to types of treatment by practitioners & 2 & 1 & 1 & 1 \\
\hline 24. Conclusions justified by sample, measures, and data analysis & 2 & 2 & 2 & 2 \\
\hline 25. Omnibus rating & 7 & 5 & 6 & 5 \\
\hline
\end{tabular}


at 12 months. Their primary outcome was reduction in depressive symptoms of at least $50 \%$ compared with baseline as measured by the BDI. After 6 months, participants in the intervention group had a BDI score that was 5.7 points lower (less depressed). At 12-month follow-up, participants had a mean BDI score of 17.0. Hence, CBT as an adjunct to TAU was effective in reducing depressive symptoms in patients with TRD and effects were maintained over 12 months.

In 2016, a long-term follow-up study derived from the above-mentioned RCT was conducted by Wiles et al. ${ }^{11}$ with the aim of assessing the long-term effectiveness of CBT as an adjunct to TAU. Patients from the first study ${ }^{10}$ were eligible for this one ${ }^{11}$ if they had not withdrawn during the 12 months' follow-up period. The primary outcome of the CoBalT follow-up was self-report of depressive symptoms assessed by the BDI score. One hundred and thirty-six of the 469 participants from the original CoBalT study ${ }^{10}$ participated in the follow-up CoBalt study. ${ }^{11}$ At trial entry, participants had a mean BDI score of 31.8 , whereas at 46 months, the mean BDI score had reduced to 19.2, which was a similar score to results at 6 and 12-month follow-ups. CBT as an adjunct to TAU was effective in reducing depressive symptoms in patients with TRD and the effects were maintained over 46 months (3-5 years).

Table 3 - Randomized controlled trials of Psychotherapy Quality Rating Scale scores for long-term follow-up studies derived from samples randomized in Randomized controlled trials of cognitive-behavioral therapy for treatment-resistant depression

\begin{tabular}{|c|c|c|}
\hline & Wiles $^{14}$ & Emslie $^{16}$ \\
\hline \multicolumn{3}{|l|}{ Description of subjects } \\
\hline 1. Diagnostic method and inclusion/exclusion criteria & 2 & 2 \\
\hline 2. Documentation/demonstration of reliability of diagnostic methodology & 2 & 1 \\
\hline 3. Description of relevant comorbidities & 2 & 2 \\
\hline 4. Description of numbers of subjects screened, included, and excluded & 2 & 2 \\
\hline \multicolumn{3}{|l|}{ Definition and delivery of treatment } \\
\hline $\begin{array}{l}\text { 5. Treatment(s) (including control/comparison groups) are sufficiently described or referenced to } \\
\text { allow for replication }\end{array}$ & 2 & 2 \\
\hline 6. The treatment being studied is treatment delivered & 2 & 2 \\
\hline 7. Therapist training and level of experience in the treatment(s) under investigation & 2 & 2 \\
\hline 8. Therapist supervision while treatment is being provided & 2 & 2 \\
\hline 9. Description of concurrent treatments allowed and administered & 1 & 2 \\
\hline \multicolumn{3}{|l|}{ Outcome measures } \\
\hline 10. Validated outcome measure(s) & 2 & 1 \\
\hline 11. Primary outcome measure(s) specified in advance & 2 & 2 \\
\hline 12. Outcome assessment by raters blinded to treatment group and with established reliability & 0 & 1 \\
\hline 13. Discussion of safety and adverse events during study treatment(s) & 0 & 2 \\
\hline 14. Assessment of long-term post-termination outcome & 1 & 1 \\
\hline \multicolumn{3}{|l|}{ Data analysis } \\
\hline 15. Intent-to-treat method for data analysis, primary outcome & 2 & 2 \\
\hline 16. Description of dropouts and withdrawals & 2 & 2 \\
\hline 17. Appropriate statistical tests & 1 & 1 \\
\hline 18. Adequate sample size & 1 & 2 \\
\hline 19. Appropriate consideration of therapist and site effects & 1 & 2 \\
\hline \multicolumn{3}{|l|}{ Treatment assignment } \\
\hline 20. A priori relevant hypotheses that justify comparison group(s) & 2 & 2 \\
\hline 21. Comparison group(s) from same population and time frame as experimental group & 2 & 2 \\
\hline 22. Randomized assignment to treatment groups & 2 & 2 \\
\hline \multicolumn{3}{|l|}{ Overall quality of study } \\
\hline 23. Balance of allegiance to types of treatment by practitioners & 1 & 2 \\
\hline 24. Conclusions justified by sample, measures, and data analysis & 2 & 2 \\
\hline 25. Omnibus rating & 6 & 7 \\
\hline
\end{tabular}

98 - Trends Psychiatry Psychother. 2020;42(1) 
Lopez and Basco's study ${ }^{12}$ was also a randomized controlled trial designed to assess the effectiveness of CBT in patients with TRD. 166 participants (19 to 74 years old and mostly Hispanic) were randomly assigned to a CBT + TAU group (83 participants, mean age 42.8 ) or to a TAU alone group (83 participants, mean age 43.2). Only those who had failed to achieve full remission of depression after two trials of medication and who had a Quick Inventory of Depressive Symptomatology (QIDS) score of 11 or greater (which means moderate symptomatology) were eligible to receive CBT consisting of 18 individual sessions. The baseline mean QIDS score was 17.9 and mean BDI score was 38.9. The results showed that, utilizing the final QIDS score, $36.7 \%$ of participants in CBT group had a clinically significant response to treatment (50\% decrease) compared to $22.9 \%$ of those in the TAU group. Utilizing the BDI score, $57.5 \%$ demonstrated meaningful response to CBT.

Finally, for adolescent populations, only one randomized controlled trial was found in the database results that assessed the efficacy of CBT in TRD adolescents: the TORDIA randomized controlled trial, published in 2008. ${ }^{3}$ The main outcome of this trial was improvement of depressive symptoms measured by validated scales. Participants were 334 adolescents aged 12 to 18 years (mean age 15.9 ), with clinically significant depression measured by the Children's Depression Rating Scale Revised (CDRS-R) with a total score of at least 4 (at least moderate severity), despite being on treatment with an SSRI for at least 8 weeks ( $40 \mathrm{mg} /$ day of fluoxetine or its equivalent). They were randomly assigned for 12 weeks to 1 of 4 treatment regimens: 1 ) switch to a second, different SSRI, 2) switch to a second, different SSRI + CBT, 3) switch to venlafaxine or 4) switch to venlafaxine + CBT with 12 months' follow-up. Medication sessions lasted 30 to 60 minutes whereas CBT was 12 sessions of 60 to 90 minutes each. $54.8 \%$ of participants treated with $\mathrm{CBT}$ showed an adequate clinical response and a reduction in CDRS-R score $(\geq 50 \%)$. CBT plus a switch to either medication showed a higher response rate $(54.8 \%)$ than a medication switch alone $(40.5 \%)$, but there was no difference in response rate between venlafaxine and a second SSRI.

In 2010, Emslie et al. ${ }^{13}$ published a long-term follow-up study derived from the above-mentioned RCT, this time with the purpose of reporting on the outcome of participants in the TORDIA trial after 24 weeks of treatment. The same participants were included, however, following the initial 12 weeks, responders remained in the same blinded treatment arm for an additional 12 weeks. Medication visits were monthly, whereas CBT visits (mean of 2.8 sessions) were every other week for 2 months and monthly thereafter. Of the 334 adolescents, only 261 participants (78.1\%) were included in the 24-week assessment and $20 \%$ did not complete the assessment. Result showed that only $38.9 \%$ of 334 adolescents from the TORDIA trial achieved remission by 24 weeks.

\section{Open trial and case report studies}

An open trial by Miller et al. ${ }^{14}$ enrolled 6 female patients aged between 20 and 64 (mean age 39.7) who met the criteria of major depressive disorder, with an initial Beck Depression Inventory (BDI) score $\geq 19$ and an initial Hamilton Depression Rating Scale (HDRS) score $\geq 17$ with a failure to respond to an adequate trial of antidepressant medication (greater than 150 $\mathrm{mg}$ of imipramine or equivalent for three weeks). All 6 female patients received a mean of 28 sessions of CBT treatment with pharmacotherapy over a period averaging 22 weeks. Results showed that the mean BDI score dropped from 25.2 to 6.3 and the mean HDRS score from 23.8 to 8.7 . In other words, $67 \%$ exhibited complete improvement on measures of depression symptomatology (BDI $\leq 9$ and HDRS $\leq 7$ ).

Moreover, Bannan ${ }^{15}$ demonstrated through the use of a case study the effectiveness of applying CBT in the treatment of resistant depression. The case study is of a 25-year-old woman with an 18-month history of resistant depression who failed to respond to three therapeutic trials of antidepressants (paroxetine 50 $\mathrm{mg} /$ day for six weeks, sertraline $150 \mathrm{mg} /$ day for four weeks and venlafaxine $225 \mathrm{mg} /$ day for three weeks). Treatment was a CBT intervention of 12 sessions using validated scales such as the BDI, Beck Hopelessness Inventory (BHI) and Beck Anxiety Inventory (BAI) (for more details please see Table 1 ). Measurements were made pre-therapy, mid-therapy and post-therapy. The results showed that following 12 sessions of $C B T$, given in combination with a course of venlafaxine $375 \mathrm{mg}$ daily, there were clear improvements in mood and in levels of hopelessness as well as in overall social and occupational functioning. These improvements were reflected in the rating scales: pre-therapy (BDI score $=31$, BHI score $=16$ ), mid-therapy (BDI score $=25$, $\mathrm{BHI}$ score $=13$ ) and post-therapy (BDI score $=16$, BHI score $=7$ ). The patient benefited from the combination of CBT + TAU.

\section{Discussion}

\section{Summary of evidence}

This review systematically evaluated the efficacy of CBT for TRD in participants aged at least 12 years, based upon evidence from controlled studies that used 
validated instruments and scales. A recent article $^{7}$ systematically reviewed the effectiveness of CBT for TRD patients, including other related types of therapies. However, to our knowledge, this is the first systematic review examining the efficacy of CBT only for treatment of resistant depression, including randomized controlled studies, open trials and case reports. It is also the first to review the efficacy of CBT on TRD for both adult and adolescent populations. Seventeen out of an initial list of 1580 articles were assessed for eligibility and 8 were included in this systematic review, comprising 6 randomized controlled trials, two of which described results for a follow-up period, 1 open trial and 1 case report. The randomized controlled trials demonstrated that the combination of CBT and TAU showed more rapid improvement in depressive symptoms. Overall, the evidence is sufficiently robust to confirm the efficacy of CBT for treatment of resistant depression in adult populations. One of the studies also showed that the effects of CBT can last for up to 3 to 5 years. The open trial also showed that symptoms are rapidly alleviated when CBT is combined with pharmacotherapy. Additionally, the case study of a woman who underwent CBT also demonstrated reduction in depressive symptomatology. All of these results were based on use of validated scales to assess depressive symptoms over 12 months of followup and even as much as 46 months of follow-up.

Just one randomized controlled trial showed that the combination CBT + TAU was also effective in an adolescent population. It is known to be the first clinical trial to enroll adolescents with depression who were not responding to an evidence-based treatment. However, when a follow-up of the same study was conducted, the results showed that the effects of CBT did not last up to 24 weeks. The findings could be applicable to community samples, which, while often more ethnically diverse than the study sample, have comparable clinical complexity.

Results address a relevant and important issue in the clinical aspect of a highly prevalent disease. When depressed patients do not respond to evidence-based interventions, healthcare providers and mental health experts should think of other strategies to manage these patients. This systematic review will help mental health experts by providing robust evidence that combination treatment for TRD patients is a choice that should be considered in their management, since it shows promising results for alleviation and reduction of depressive symptoms.

\section{Limitations}

There are several limitations to consider when interpreting this review. The first is that only four randomized controlled trials addressed this topic. ${ }^{6,10,12}$ Moreover, only one randomized controlled trial ${ }^{3}$ studied an adolescent population. Furthermore, there were insufficient data to conduct a meta-analysis, hence the absence of such an analysis in our systematic review.

\section{Conclusions}

The difficulty of treating patients with TRD poses considerable challenges to healthcare providers and mental health experts. The challenge is greater because of the limited number of studies. Since the available findings are interesting and some demonstrate the efficacy of CBT for TRD patients, this study has provided further support for the contention that adding CBT to TRD treatment is a promising and effective approach. Significantly more CBT patients had clinically meaningful reductions in symptoms, according to the validated scales of depression used in the studies reviewed. However, it should be noted that there is a need to conduct additional studies of this topic. More specifically, further research is needed to investigate in greater detail whether adding CBT to TRD is beneficial in adolescents, since $40 \%$ of them will not respond to TAU treatment.

\section{Disclosure}

No conflicts of interest declared concerning the publication of this article.

\section{References}

1. Trevino K, McClintock SM, McDonald Fischer N, Vora A, Husain MM. Defining treatment-resistant depression: a comprehensive review of the literature. Ann Clin Psychiatry. 2014;26:222-32.

2. Fava M. Diagnosis and definition of treatment-resistant depression. Biol Psychiatry. 2003;53:649-59.

3. Brent D, Emslie G, Clarke G, Wagner KD, Asarnow JR, Keller M, et al. Switching to another SSRI or to venlafaxine with or without cognitive behavioral therapy for adolescents with SSRI-resistant depression: the TORDIA randomized controlled trial. JAMA. 2008;299:901-13.

4. Bergfeld IO, Mantione M, Figee M, Schuurman PR, Lok A, Denys D. Treatment-resistant depression and suicidality. J Affect Disord. 2018;235:362-7

5. McIntyre RS, Filteau MJ, Martin L, Patry S, Carvalho A, Cha DS, et al. Treatment-resistant depression: definitions, review of the evidence, and algorithmic approach. J Affect Disord. 2014;156:17.

6. Nakagawa A, Mitsuda D, Sado M, Abe T, Fujisawa D, Kikuchi $T$, et al. Effectiveness of supplementary cognitive-behavioral therapy for pharmacotherapy-resistant depression: a randomized controlled trial. J Clin Psychiatry. 2017;78:1126-35.

7. Li J, Zhang Y, Su W, Liu L, Gong H, Peng W, et al. Cognitive behavioral therapy for treatment-resistant depression: a systematic review and meta-analysis. Psychiatry Res. 2018;268:243-50.

8. Moher D, Liberati A, Tetzlaff J, Altman DG, PRISMA Group. Preferred reporting items for systematic reviews and meta-analyses: the PRISMA statement. J Clin Epidemiol. 2009;62:1006-12 
9. Kocsis JH, Gerber AJ, Milrod B, Roose SP, Barber J, Thase ME, et al. A new scale for assessing the quality of randomized clinical trials of psychotherapy. Compr Psychiatry. 2010;51:319-24.

10. Wiles N, Thomas L, Abel A, Ridgway N, Turner N, Campbell J, et al. Cognitive behavioural therapy as an adjunct to pharmacotherapy for primary care based patients with treatment resistant depression: results of the CoBalT randomised controlled trial. Lancet. 2013;381:375-84.

11. Wiles NJ, Thomas L, Turner N, Garfield K, Kounali D, Campbell $J$, et al. Long-term effectiveness and cost-effectiveness of cognitive behavioural therapy as an adjunct to pharmacotherapy for treatment-resistant depression in primary care: follow-up of the CoBalT randomised controlled trial. Lancet Psychiatry. 2016;3:137-44.

12. Lopez MA, Basco MA. Effectiveness of cognitive behavioral therapy in public mental health: Comparison to treatment as usual for treatment-resistant depression. Adm Policy Ment Health. 2015;42:87-98.

13. Emslie GJ, Mayes T, Porta G, Vitiello B, Clarke G, Wagner KD, et al. Treatment of Resistant Depression in Adolescents (TORDIA): week 24 outcomes. Am J Psychiatry. 2010;167:782-91.
14. Miller IW, Bishop SB, Norman WH, Keitner GI. Cognitive/ behavioural therapy and pharmacotherapy with chronic, drugrefractory depressed inpatients: a note of optimism. Behav Cogn Psychother. 1985;13:320-7.

15. Bannan N. Multimodal therapy of treatment resistant depression: a study and analysis. Int J Psychiatry Med. 2005;35:27-39.

16. Abel A, Hayes AM, Henley W, Kuyken W. Sudden gains in cognitivebehavior therapy for treatment-resistant depression: processes of change. J Consult Clin Psychol. 2016;84:726.

\section{Correspondence:}

Stephanie Zakhour

Ambulatório de Depressão Resistente ao Tratamento (DeReTrat) Instituto de Psiquiatria (IPUB), Universidade Federal do Rio de Janeiro (UFRJ)

Av. Vencelaus Brás, 71, Campus da Praia Vermelha

22290-140 - Rio de Janeiro, RJ - Brazil

Tel. : + 55 (21) 964426645

E-mail: stephaniezakhour@hotmail.com 